\title{
Dual-Band Integrated Antennas for DVB-T Receivers
}

\author{
Andrea D'alessandro, ${ }^{1}$ Roberto Caso, ${ }^{1}$ Marcos R. Pino, ${ }^{2}$ and Paolo Nepa ${ }^{1}$ \\ ${ }^{1}$ Department of Information Engineering, University of Pisa, I-56122 Pisa, Italy \\ ${ }^{2}$ Department of Electrical Engineering, University of Oviedo, 3203 Gijón, Spain
}

Correspondence should be addressed to Roberto Caso; roberto.caso@iet.unipi.it

Received 6 December 2012; Accepted 30 March 2013

Academic Editor: Renato Cicchetti

Copyright (C) 2013 Andrea D'alessandro et al. This is an open access article distributed under the Creative Commons Attribution License, which permits unrestricted use, distribution, and reproduction in any medium, provided the original work is properly cited.

\begin{abstract}
An overview on compact Planar Inverted-F Antennas (PIFAs) that are suitable for monitor-equipped devices is presented. In particular, high efficiency PIFAs (without any dielectric layer) with a percentage bandwidth (\%BW) greater than $59 \%(470-862 \mathrm{MHz}$ DVB-T band) are considered. In this context, two PIFA configurations are reviewed, where a dual-band feature has been obtained, in the $3300-3800 \mathrm{MHz}$ (14\% percentage bandwidth) WiMAX and $2400-2484 \mathrm{MHz}$ (2.7\% percentage bandwidth) WLAN IEEE $802.11 \mathrm{~b}, \mathrm{~g}$ frequency bands, respectively, to also guarantee web access to on-demand services. The two PIFAs fill an overall volume of $225 \times 31 \times 20 \mathrm{~mm}^{3}$ and $207 \times 12 \times 8 \mathrm{~mm}^{3}$, respectively. They are composed of a series of branches, properly dimensioned and separated to generate the required resonances. Finally, to show the extreme flexibility of the previous two configurations, a novel dual-band L-shape PIFA has been designed. A reflection coefficient less than $-6 \mathrm{~dB}$ and $-10 \mathrm{~dB}$ and an antenna gain of around $2 \mathrm{dBi}$ and $6.3 \mathrm{dBi}$ have been obtained in the $470-862 \mathrm{MHz}$ DVB-T band and the $2400-2484 \mathrm{MHz}$ WLAN band, respectively. The L-shape PIFA prototype can be obtained by properly cutting and folding a single metal sheet, thus resulting in a relatively low-cost and mechanically robust antenna configuration.
\end{abstract}

\section{Introduction}

Many countries already switched their terrestrial television broadcasting from analog to Digital Video BroadcastingTerrestrial (DVB-T) [1]; besides, the demand for digital television reception is increasing also for mobile terminals, such as smart phones and notebooks, which include web access through Wireless Local Area Networks (WLANs) as well. Due to the severe space limitations of typical monitorequipped devices, dual-band compact integrated antennas for DVB-T and WLAN applications are more attractive than a couple of distinct single-band antennas. Several wideband antennas suitable for DVB-T applications (percentage bandwidth greater than 59\%) have been recently presented [2-16]. Among them, PIFAs are those more suitable for integration into multifunctions devices with a high density of electronic circuits; indeed, their own ground plane acts as an electromagnetic shield and the 3D structure helps in enlarging impedance bandwidth. Also, multiple frequency bands can be achieved by adding more resonating paths [17]. A linear-shape PIFA working in the DVB-T and WIMAX frequency bands has been presented in [18]. Moreover, an alternative layout for a dual-band linear-shape PIFA has been more recently proposed in [19], for an antenna operating in the DVB-T and WLAN frequency bands. Since the PIFAs in $[18,19]$ cannot be made shorter than $20 \mathrm{~cm}$, while still getting an acceptable input impedance matching at the DVB-T frequency band, some other layout modifications are needed for integration into those devices with a length of the monitor sides not greater than $13-15 \mathrm{~cm}$, or when part of the space along the monitor border is occupied by a webcam or a microphone. In such cases, a possible modification of the antenna layout with respect to that in $[18,19]$ is based on conforming the antenna to the shape of one of the device corners (a few preliminary simulation results were presented in [20]). In this paper, both numerical simulations and experimental results for an L-shape PIFA layout derived from that in [19] are presented, to show that the modified layout can be a valuable solution for monitor-equipped devices with an extent smaller than $15 \mathrm{~cm} \times 15 \mathrm{~cm}$. Simulation results have been derived by using CST Microwave Studio commercial tool. 


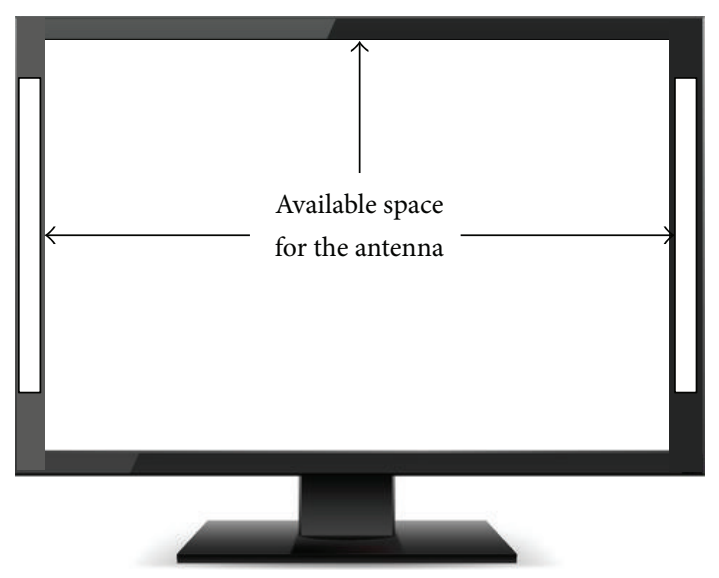

FIGURE 1: Example of a typical monitor chassis; the available space for the antenna is highlighted in a light color.

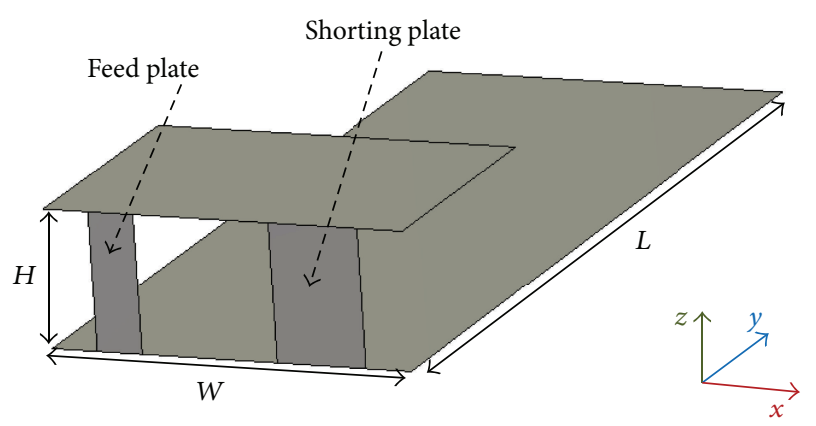

FIGURE 2: A PIFA where bandwidth enlargement can be achieved by optimizing the widths of the feeding and shorting plates [12].

\section{Overview on Wideband and High Efficiency Compact Planar Inverted-F Antennas}

In Figure 1, a typical TV chassis is shown, where possible spaces available to locate an antenna are also highlighted. A number of DTV wideband antennas have been recently presented [2-11], which are mainly low-cost, low-profile, and easy-fabrication printed monopoles and patch-alike antennas. Printed monopoles require a careful positioning inside devices with high circuitry density, as they are quite sensitive to the presence of nearby metal parts. On the other hand, patch-alike antennas and PIFAs are suitable for integration because their ground plane also acts as a shield.

In this section, a review of some high efficiency (without any dielectric layer) PIFAs will be presented. In particular, antennas with a percentage bandwidth greater than $59 \%$ (i.e., the DVB-T \%BW) have been taken into account. These antennas are suitable to be integrated into devices, such as a monitor or a TV chassis, where relatively large volumes are often available along their borders.

In [12], a PIFA with a percentage bandwidth of $65 \%$ and operating in the $1.6-3 \mathrm{GHz}$ band for mobile applications (GSM, PCS, DCS, UMTS, WLAN, WiMax, and Bluetooth) has been presented. A so large impedance bandwidth can be

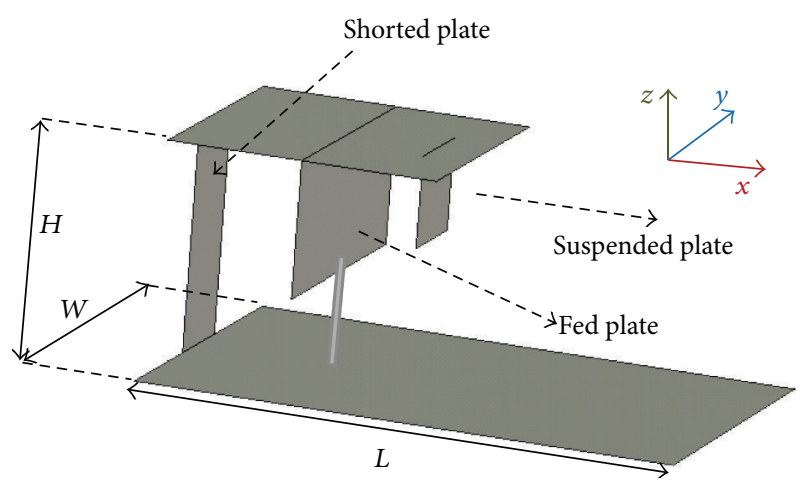

FIGURE 3: A PIFA consisting of a planar rectangular monopole toploaded with a rectangular patch attached to two rectangular plates, one is shorted to the ground and the other is suspended [13].

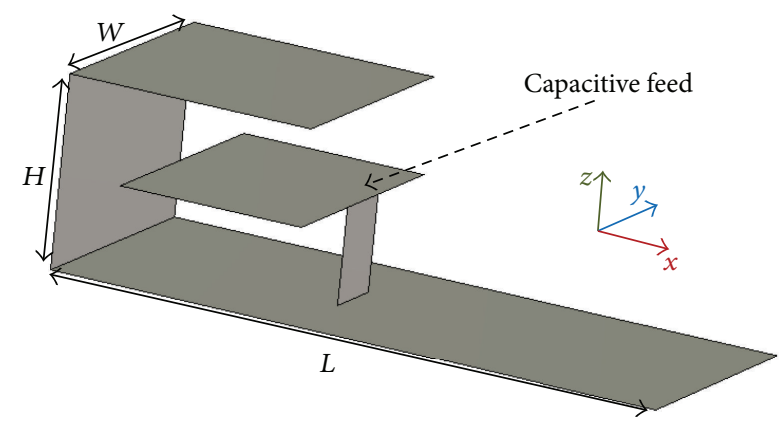

FIGURE 4: A PIFA where a large impedance bandwidth has been obtained by using a capacitive feeding [14].

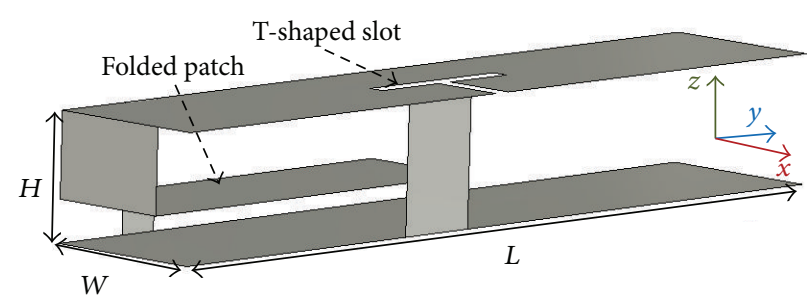

Figure 5: The inclusion of a T-shaped slot as well as a folded patch results in a wide impedance bandwidth in the PIFA presented in [15].

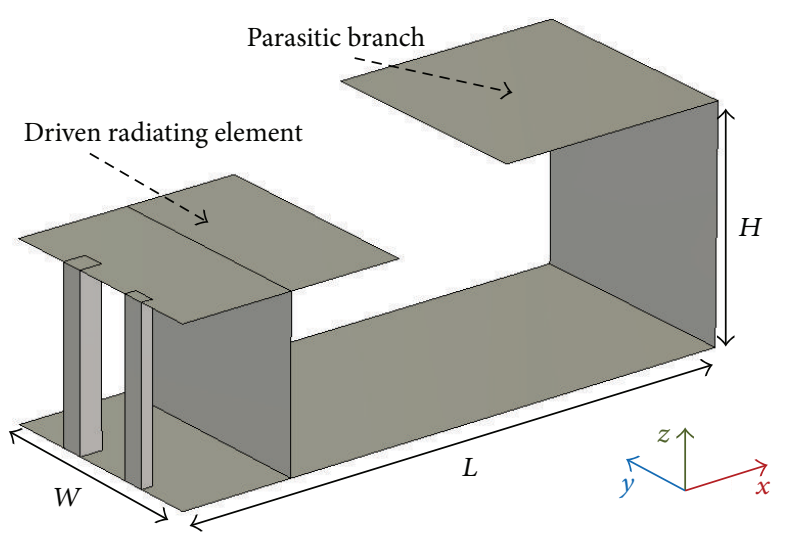

FIgURE 6: A PIFA characterized by a driven (fed) radiating element separated by a small gap from a parasitic branch [16]. 


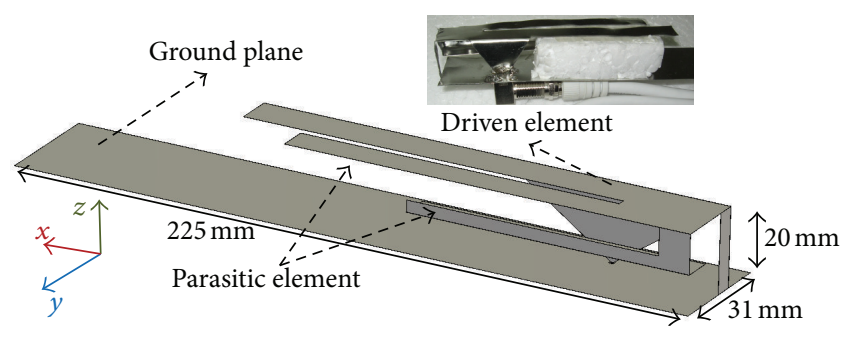

Figure 7: Conf. A: 3D view.

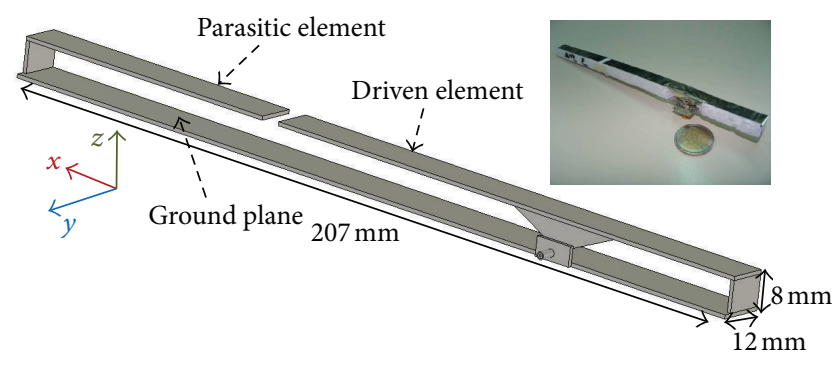

Figure 8: Conf. B: 3D view.

achieved by optimizing the widths of the feeding and shorting plates (Figure 2).

In [13], a PIFA configuration has been presented (Figure 3) which is made of a planar rectangular monopole top-loaded with a rectangular patch attached to two rectangular plates, one shorted to the ground and the other suspended. The fabricated antenna prototype has a measured impedance bandwidth of $125 \%$ (reflection coefficient lower than $-10 \mathrm{~dB}$ in the $3-13 \mathrm{GHz}$ band). The radiator size is $20 \times 10 \times 7.5 \mathrm{~mm}^{3}$, making the antenna electrically small over most of the band and suitable for integration in mobile devices.

In [14], a capacitive feed is used to improve impedance characteristics (Figure 4). By changing three parameters (the area of the feed plate, the separation from the radiating top plate, and probe placement on the feed plate), antenna resonances can be controlled. The proposed design exhibits an impedance bandwidth ranging from $1.18 \mathrm{GHz}$ to $2.24 \mathrm{GHz}$ (61.92\%).

In [15], a modified PIFA (Figure 5) with a compact size of $34 \mathrm{~mm} \times 8.0 \mathrm{~mm} \times 8.0 \mathrm{~mm}$ has been proposed. The uniqueness of this design is the inclusion of both a T-shaped slot and a folded patch. The compact PIFA has a very wide $77 \%$ 10-dB impedance bandwidth (a larger bandwidth up to $81.3 \%$ has been measured on the prototype).

A UWB PIFA for the $2.4-6.2 \mathrm{GHz}$ band (88.4\% relative bandwidth), which is characterized by a driven (fed) radiating element separated by a small gap from a parasitic branch (Figure 6), has been presented in [16].

Starting from the previous configurations, two high efficiency PIFAs have been presented in [18-20] for DVB-T band. A dual band functionality has been obtained by adding a new path in the antenna layout [18] or by using the small gap between the feed element and the parasitic one $[19,20]$.

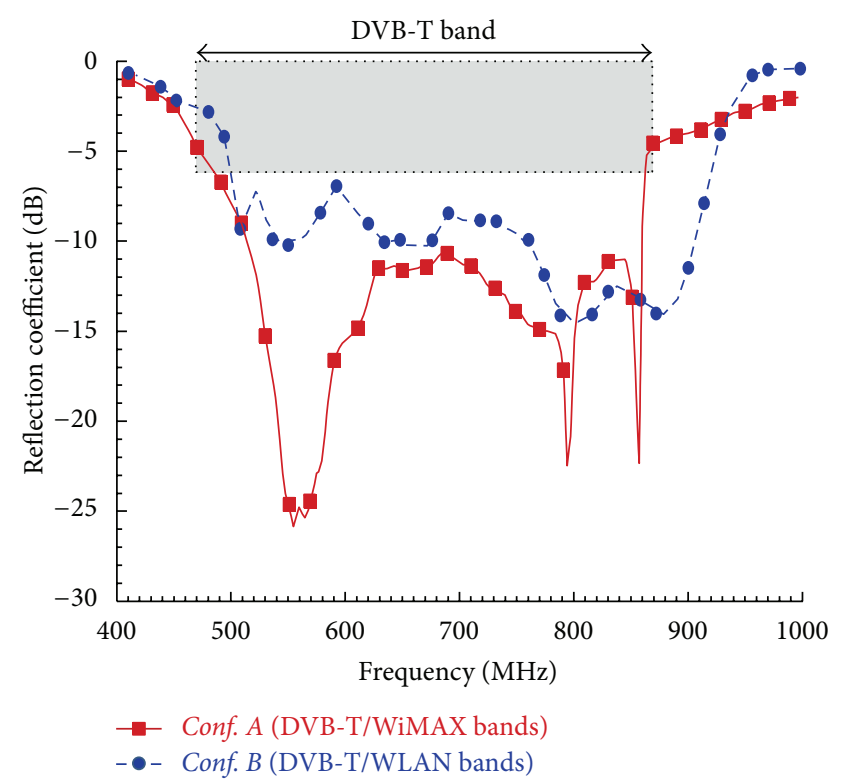

FIGURE 9: Measured reflection coefficient for the two PIFAs in [16, 18], in the DVB-T band.

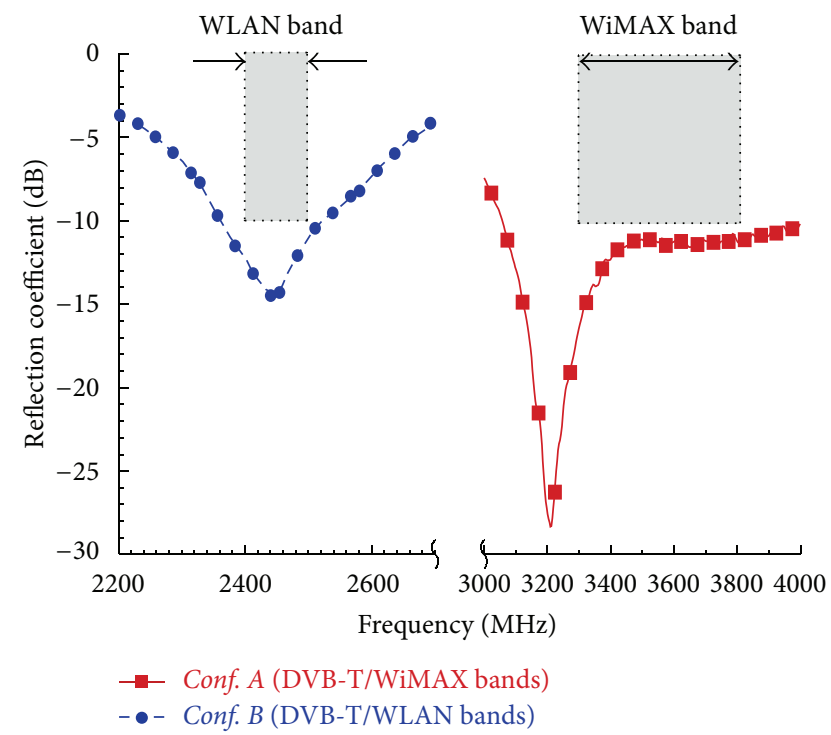

FIGURE 10: Measured reflection coefficient for the two PIFAs in [16, 18], in the WiMAX and WLAN bands, respectively.

Figure 7 shows the layout, the antenna prototype, and the main parameters of the PIFA proposed in [18] (named as Conf. $A$ as shown in Figure 7).

Conf. A antenna (Figure 7) is composed of a series of branches, properly dimensioned and separated to generate the required resonances. The antenna exhibits a multiband functionality between $470 \mathrm{MHz}$ and $862 \mathrm{MHz}$ (59\% percentage bandwidth) and between $3300 \mathrm{MHz}$ and $3800 \mathrm{MHz}(14 \%$ percentage bandwidth) for DVB-T and WiMAX applications, respectively. The final layout resulted from an optimization process focused to reduce the overall antenna dimensions as much as possible. The prototypes were fabricated with 


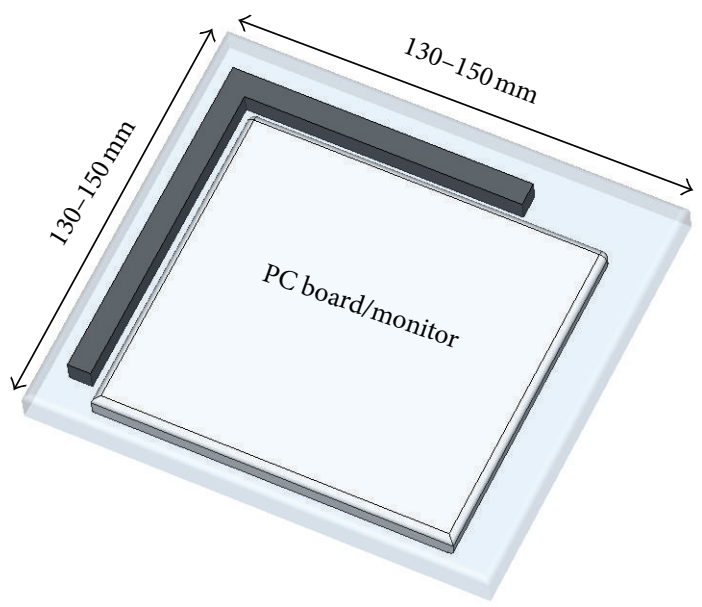

Figure 11: Example of a 3D view of a typical monitor chassis. The available space for the antenna is dark highlighted.

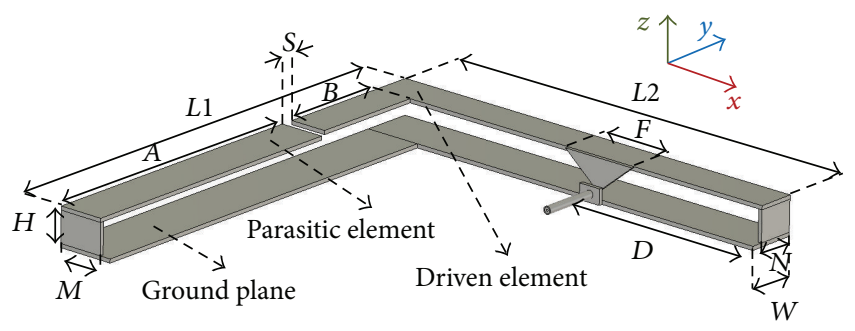

FIGURE 12: Geometry of the proposed dual-band L-shape PIFA.

a $0.4 \mathrm{~mm}$ thick aluminum foil, properly cut and folded. This simplifies the antenna fabrication and avoids any soldering, except for that at the antenna connector.

The extent of the antenna proposed in [16] was also reduced in terms of wavelength in $[19,20]$, for the DVB-T and WLANs bands (named as Conf. $B$ as shown in Figure 8).

The driven PIFA element acts as the primary element, governing the lowest resonant frequency, while the upper resonant frequency close to the DVB-T band is controlled by the parasitic element. Moreover, the separating gap helps in controlling a third resonance around $2.45 \mathrm{GHz}$ in the IEEE $802.11 b, g$ band for WLANs. Thus, as an improvement of the solution in [16], the proposed PIFA exhibits a dual band functionality. Moreover, if compared with [16], a significant reduction of $63 \%$ and $87 \%$ was achieved for the electrical thickness $(H)$ and width $(W)$, respectively (the electrical size is referred to the wavelength at the DVB-T band center frequency, where $\lambda=448 \mathrm{~mm}$ ) at the cost of only $9 \%$ length $(L)$ increase.

The $50 \Omega$-impedance matching was met for the two configurations (Conf. $A$ and Conf. $B$ ) by optimizing the feeding plate shapes (the triangular plates connecting the feeding cables to the radiating elements in Figures 7 and 8) and the position of the shorting strip. The two PIFAs occupy an overall volume of $225 \times 31 \times 20 \mathrm{~mm}^{3}$ and $207 \times 12 \times 8 \mathrm{~mm}^{3}$, respectively. These radiating elements are relatively large with respect to antennas printed or mounted on high permittivity

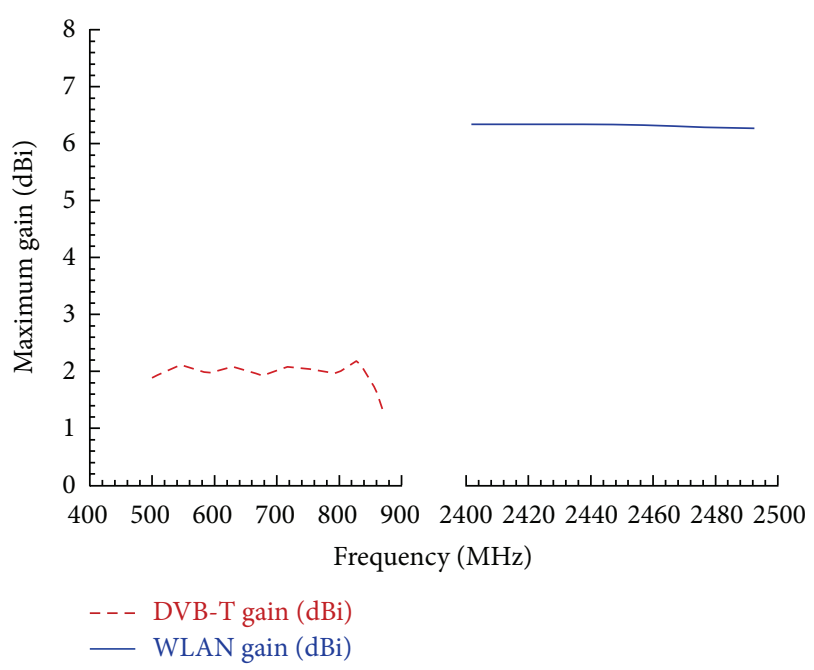

FIGURE 13: Simulated gain for the proposed dual-band L-shape PIFA as a function of frequency.

substrates, but, at the same time, they can guarantee higher gains and radiation efficiencies.

As shown in Figures 9 and 10, the measured reflection coefficients for Conf. $A$ and Conf. B PIFAs are below $-6 \mathrm{~dB}$ in the whole DVB-T band for both configurations and less than $-10 \mathrm{~dB}$ in the WiMAX and IEEE $802.11 \mathrm{~b}, \mathrm{~g}$ bands, respectively. The previous values are typical thresholds for integrated antennas for such communication standards.

The resonances in the DVB-T band for the two antenna configurations are mainly due to the plates of length $L$ and the branches of length $A$ and $B$. The PIFA height $H$ is a critical parameter for obtaining the antenna impedance matching. For the Conf. $A$ antenna, gain lies between 2.8 and $3.3 \mathrm{dBi}$ in the lower band and between $3.2 \mathrm{dBi}$ and $4.0 \mathrm{dBi}$ in the WiMAX band.

The gain for the Conf. $B$ is between $2.4 \mathrm{dBi}$ and $3.3 \mathrm{dBi}$ in the DVB-T band and between $4.4 \mathrm{dBi}$ and $4.8 \mathrm{dBi}$ in the WLAN band. The relatively high values obtained for the gain are due to the absence of a lossy dielectric under the radiating plate. A further analysis consisted in measuring the reflection coefficient variations when a metallic obstacle is located close to the antenna [19]. In particular, a large metallic plate $(300 \mathrm{~mm} \times 400 \mathrm{~mm})$ was positioned in the vicinity of the antenna, at distances of $1 \mathrm{~cm}, 2 \mathrm{~cm}$, and $3 \mathrm{~cm}$. The numerical results demonstrated that the reflection coefficient variations are minimal. The robustness of the solution in terms of reflection coefficient variations with respect to the presence of near metal parts has been analyzed and checked through measurements too.

\section{A Novel Dual-Band L-Shape Planar Inverted-F Antenna (PIFA)}

Starting from the dual-band linear-shape PIFA described in [19], a modified layout suitable to be integrated along the corner of a compact monitor-equipped device (as shown in Figure 11) is here presented. 

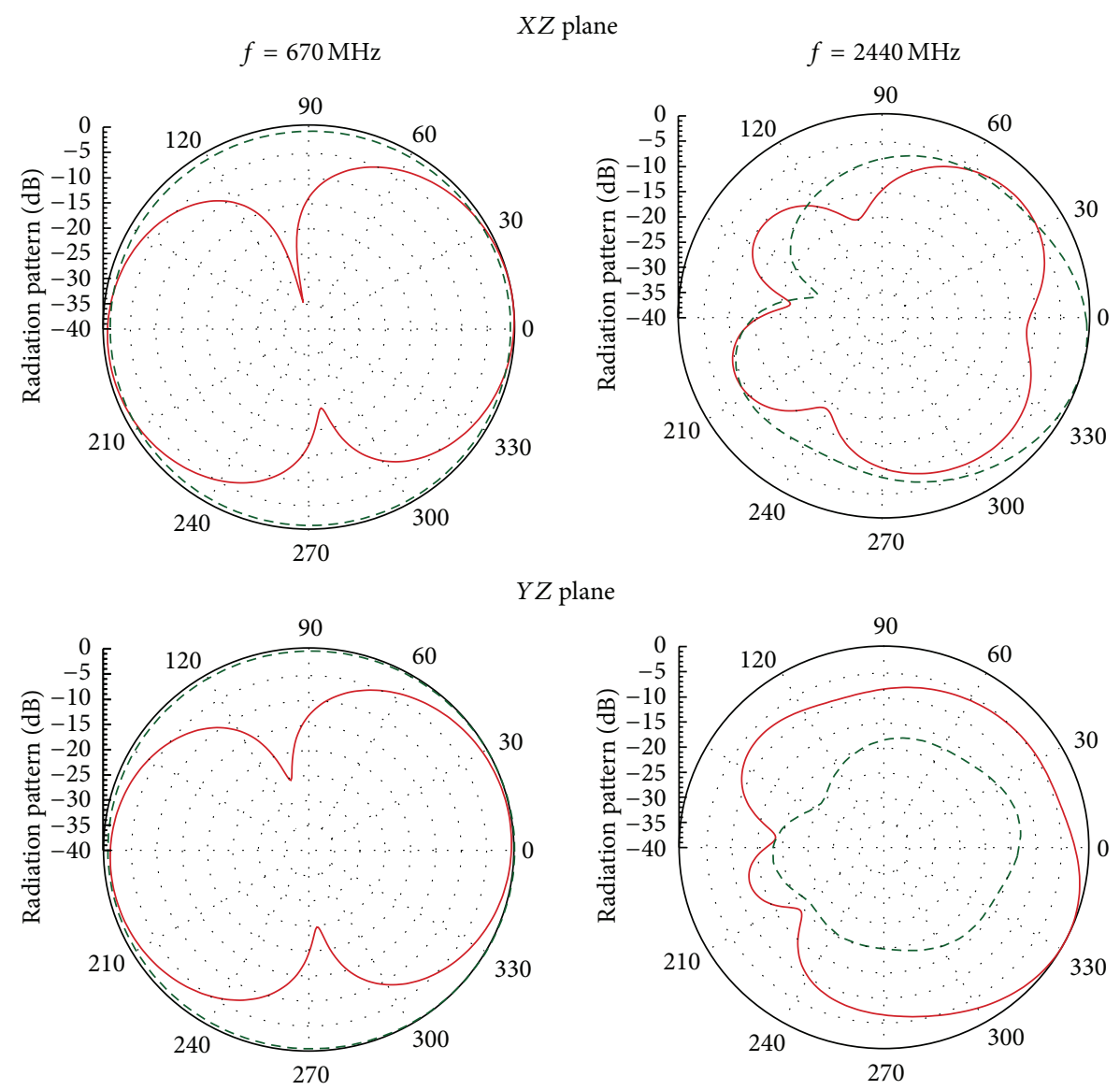

$X Y$ plane

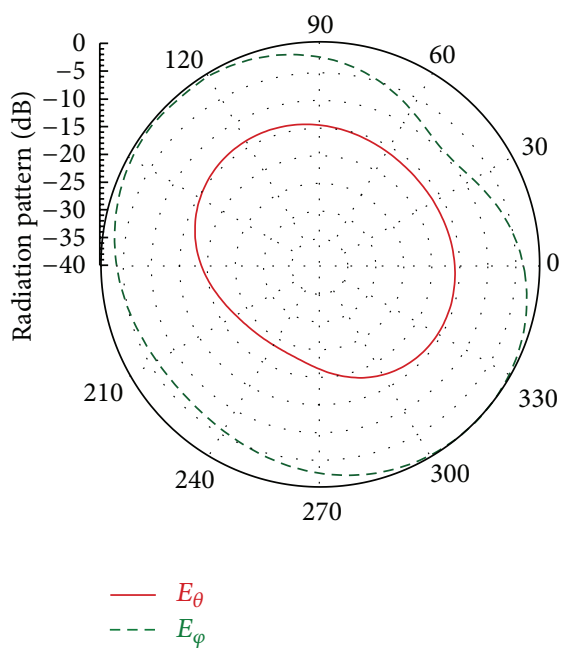

(a)

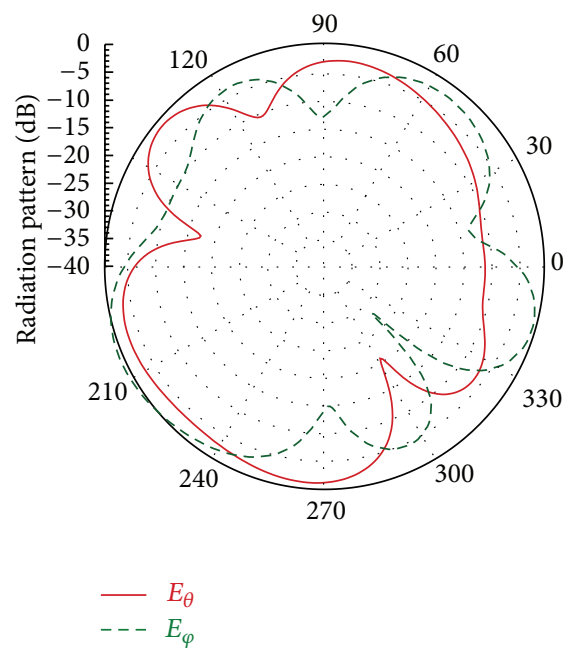

(b)

FIGURE 14: Simulated radiation patterns $\left(E_{\theta}\right.$ and $E_{\varphi}$ components normalized to the electric field amplitude at $\left.\theta=0\right)$ for the proposed dualband L-shape PIFA: (a) $670 \mathrm{MHz}$ (central frequency for the DVB-T band); (b) $2440 \mathrm{MHz}$ (central frequency for the IEEE $802.11 \mathrm{~b}, \mathrm{~g}$ band).

In [18-20], it has been verified that the total length $L$ of a linear PIFA is a key parameter to achieve impedance matching at DVB-T band, and it should be greater than $20 \mathrm{~cm}$ to get satisfactory VSWR performance in the whole DVB-T frequency range.
It is worth noting that the new L-shape antenna configuration cannot be obtained by simply bending the antenna in [19], since all the basic antenna geometrical parameters need to be modified to optimize antenna performance (Figure 12). 


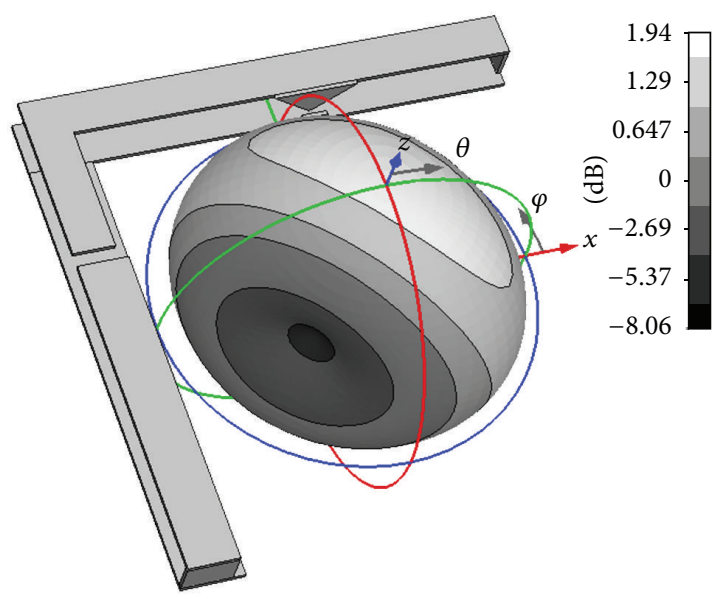

FIgURE 15: Simulated 3D antenna gain (dBi) for the dual-band Lshape PIFA at $670 \mathrm{MHz}$.

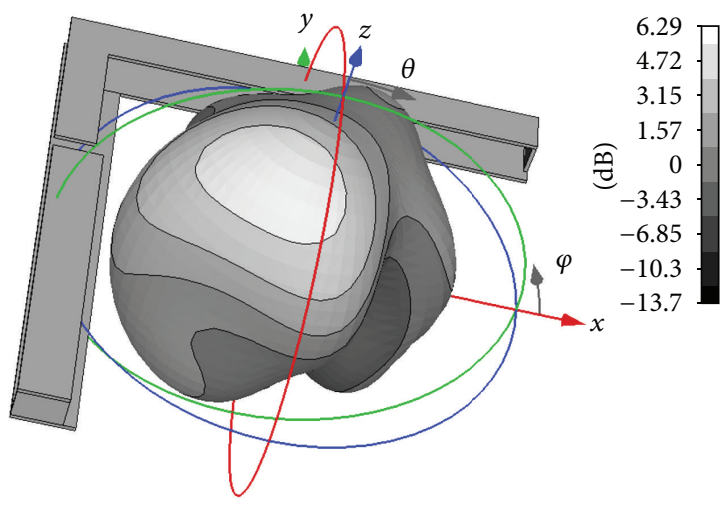

FIGURE 16: Simulated 3D antenna gain (dBi) for the dual-band Lshape PIFA at $2440 \mathrm{MHz}$.

Table 1 shows the values of all geometrical parameters of the optimized L-shape PIFA.

In particular, the driven and parasitic elements jointly contribute to determine the two resonances at the DVB$\mathrm{T}$ band. They can be controlled by varying the following parameters: $W, H, L 1$ and $L 2$. Also, the sum of the arm lengths, $L 1$ and $L 2$, must be retained greater than $20 \mathrm{~cm}$. The width and the height of the radiating element have been set at $13 \mathrm{~mm}$ and $8 \mathrm{~mm}$, respectively, as in [19]. Furthermore, the gap $S$ between the two elements mainly affects the antenna reflection coefficient at the IEEE $802.11 \mathrm{~b}, \mathrm{~g}$ band. The distance between the two radiating elements, $S$, and the distance of the feeding point from the edge, $D$, represent the most effective design parameters for antenna tuning. $M$ and $N$ variations cause the resonant frequency to shift in the IEEE 802.11b,g band; also, the reflection coefficient values increase at the DVB-T frequencies. As for the PIFAs in [18-20], the L-shape PIFA can be made out of a cut and bent single metal sheet.

3.1. Numerical Results for the Dual-Band L-Shape PIFA. Simulation results have been derived by using CST Microwave Studio commercial tool. The simulated reflection coefficient
TABLE 1: Dual-band L-shape PIFA dimensions ( $\mathrm{mm}$ ).

\begin{tabular}{lc}
\hline$L 1$ & 120 \\
$L 2$ & 116 \\
$W$ & 13 \\
$H$ & 8 \\
$S$ & 3.3 \\
$A$ & 76.5 \\
$M$ & 12 \\
$B$ & 30.2 \\
$N$ & 10 \\
$D$ & 47 \\
$F$ & 20 \\
\hline
\end{tabular}

is below $-6 \mathrm{~dB}$ and $-10 \mathrm{~dB}$ in the DVB-T and WLAN bands, respectively. The simulated antenna gain (Figure 13) is between $1.8 \mathrm{dBi}$ and $2.2 \mathrm{dBi}$ in the DVB-T band and between $6.2 \mathrm{dBi}$ and $6.4 \mathrm{dBi}$ in the WLAN band; a radiation efficiency greater than $95 \%$ has been obtained at both frequency bands due to the absence of dielectric substrates.

The radiation pattern modifications have been analyzed and compared to those of the linear-shape PIFA in [19]. The simulated radiation patterns in the principal planes, $X Z, Y Z$, and $X Y$, are shown in Figure $14\left(E_{\theta}\right.$ and $E_{\varphi}$ components, with all of them normalized to the electric field amplitude at $\theta=$ 0 ), when evaluated at the center frequency of the bands of interest. In the DVB-T band, the L-shape geometry causes a $45^{\circ}$ rotation of the radiation pattern in the $X Y$ plane, as also apparent form the antenna gain 3D plots shown in Figures 15 and 16. In the other two principal planes ( $X Z$ and $Y Z$ ), a $10^{\circ}$ displacement from broadside of the $E_{\theta}$ component maximum occurs; the $E_{\varphi}$ component exhibits an almost omnidirectional radiation pattern.

The radiation patterns in Figure 17 show that L-shape PIFA radiates a linearly polarized field in the $\varphi=+45^{\circ}$ plane. Also, it radiates as a combination of two orthogonal linear radiators that are fed in-phase. At higher frequency, in the WLAN band, a larger number of lobes is present, as expected since the antenna is electrically long at $2.4 \mathrm{GHz}$ (see Figures 14 and 16).

3.2. Experimental Results for the Dual-Band L-Shape PIFA. A prototype was realized with a $0.4 \mathrm{~mm}$ thick adhesive copper tape, cut and folded around a polystyrene block to obtain the final 3D structure. Results in terms of simulated and measured reflection coefficient are shown in Figure 18. The measured reflection coefficient is below $-6 \mathrm{~dB}$ and $-10 \mathrm{~dB}$ in the DVB-T and WLAN bands, respectively. Measurements on the radiation patterns have been performed at the anechoic chamber of the Department of Electrical Engineering of the University of Oviedo. The antenna prototype is shown in Figure 19 when it is mounted on the rotating platform for radiation pattern measurement.

The measured radiation patterns for the $X Z$ and $Y Z$ planes, at $670 \mathrm{MHz}$ and $2440 \mathrm{MHz}$, are compared with numerical simulations in Figures 20 and 21. Discrepancies between simulations and measurements are probably due 


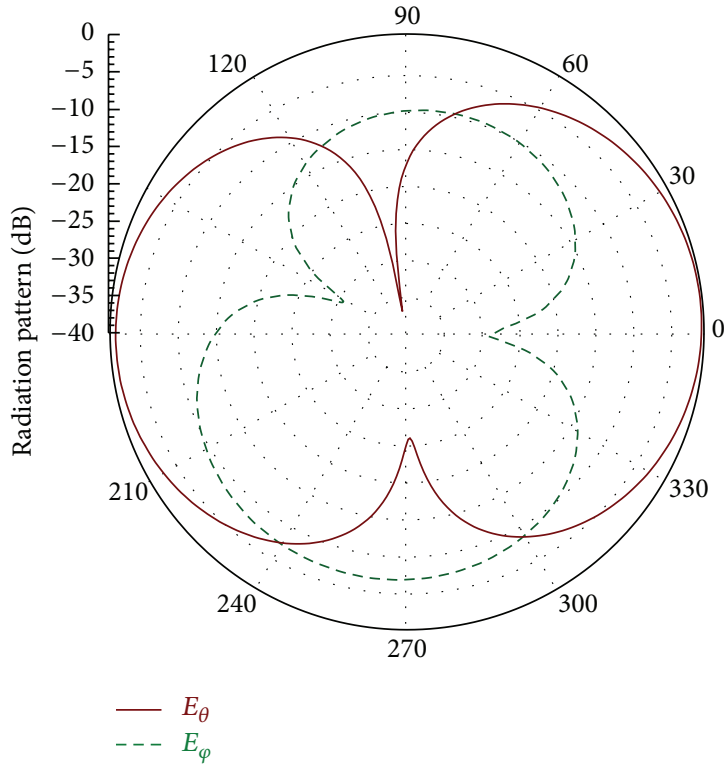

(a)

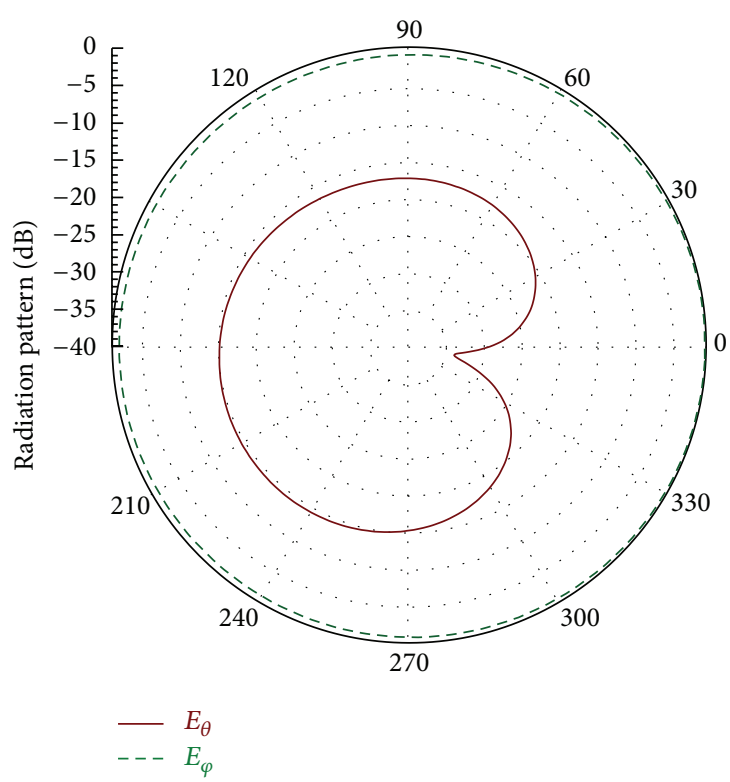

(b)

FIGURE 17: Simulated radiation patterns $\left(E_{\theta}\right.$ and $E_{\varphi}$ components normalized to the electric field amplitude at $\left.\theta=0\right)$ for the proposed dualband L-shape PIFA at $670 \mathrm{MHz}$ : (a) $\varphi=45^{\circ}$ plane; (b) $\varphi=-45^{\circ}$ plane.

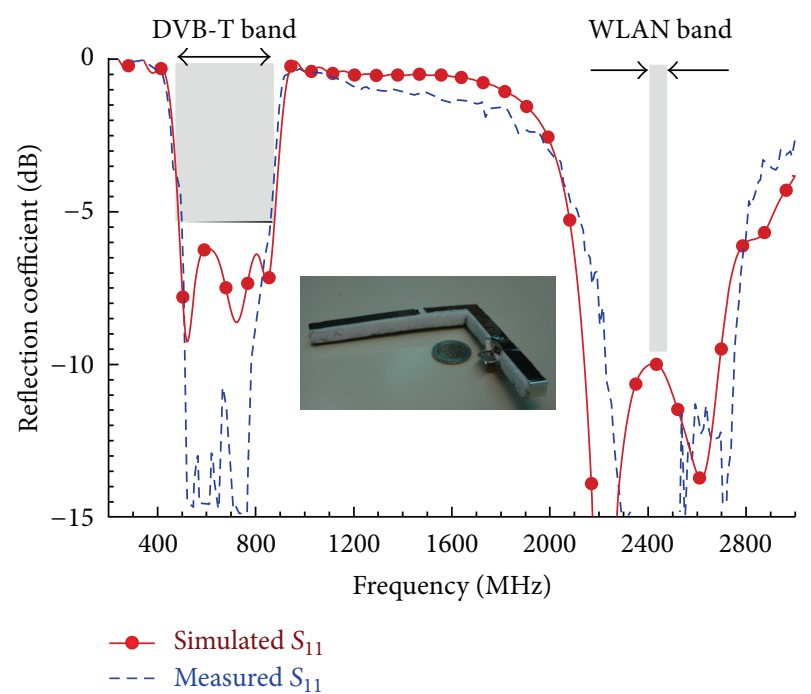

FIGURE 18: Simulated and measured reflection coefficient for the proposed dual-band L-shape PIFA.

to the limited mechanical robustness of the homemade prototype and the manufacturing inaccuracies. The measured antenna gain is about $1 \mathrm{dBi}$ and $5 \mathrm{dBi}$ for the DVB-T and the WLAN band, respectively (it is about $1 \mathrm{~dB}$ less than simulated results).

\section{Conclusions}

Starting from an overview on compact Planar Inverted-F Antennas, a dual-band L-shape Planar Inverted-F Antenna operating in both the DVB-T band $(470-862 \mathrm{MHz})$ and the

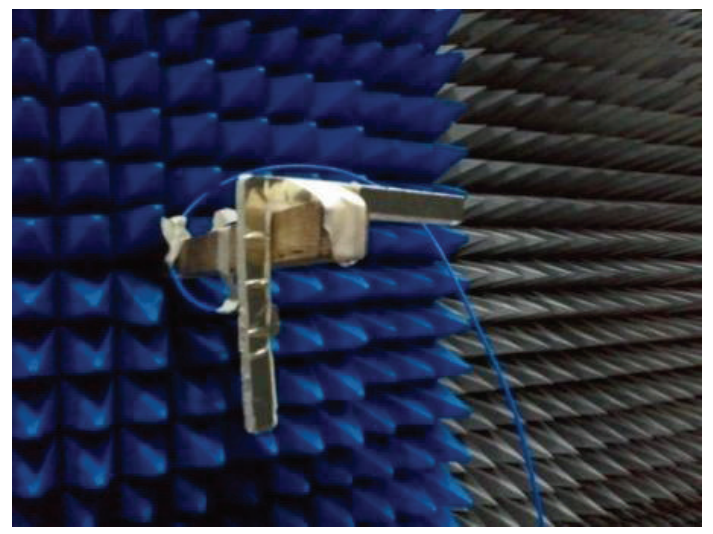

FIGURE 19: Antenna prototype mounted on the rotating platform for radiation pattern measurements.

WLAN IEEE $802.11 \mathrm{~b}, \mathrm{~g}$ band $(2400-2484 \mathrm{MHz})$ has been presented. It has been designed to meet space requirements typically required for integration along the corner of displayequipped devices. A prototype was realized and characterized. The L-shape PIFA can be obtained by properly cutting and folding a single metal sheet, thus resulting in a relatively low-cost and mechanically robust antenna configuration.

Although the final design here shown has been obtained by assuming specific requirements on the maximum length of the two arms of the L-shape PIFA (less than $15 \mathrm{~cm}$ for both arms), it has been numerically and experimentally verified that VSWR performance at the extremely large DVB$\mathrm{T}$ frequency band can be still met by properly tuning antenna geometrical parameters, when the arm length requirements change less than $10 \%$ with respect to the lengths in Table 1. 


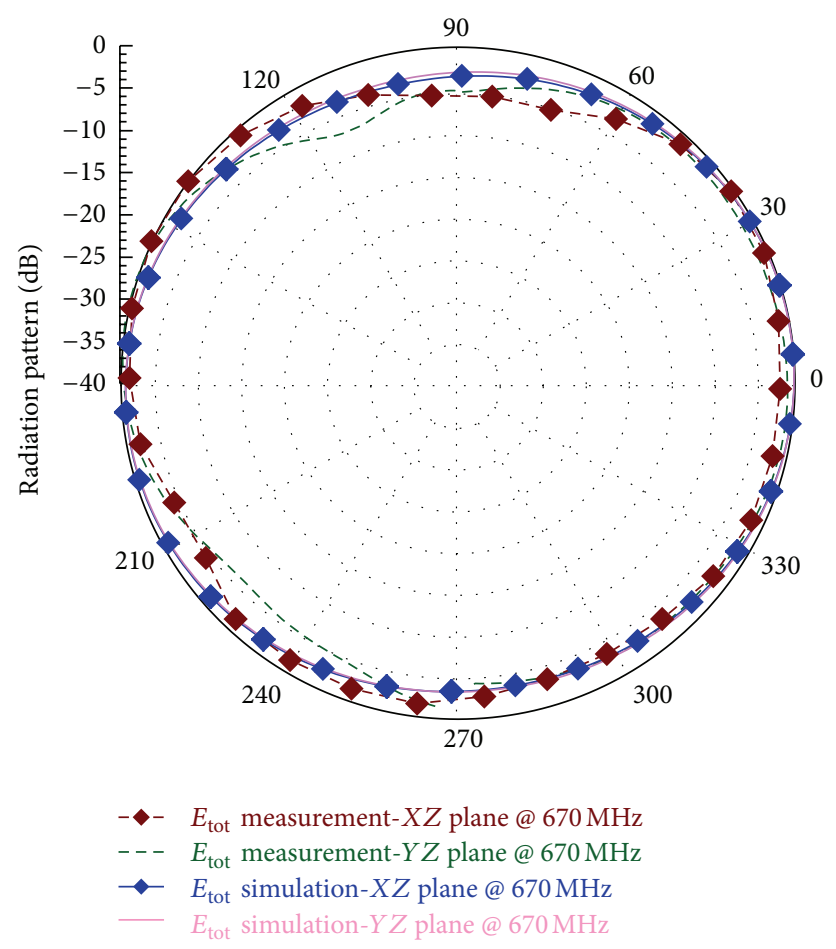

FIGURE 20: Simulated and measured radiation patterns (total E-field for the $X Z$ and $Y Z$ planes) for the proposed dual-band L-shape PIFA at $670 \mathrm{MHz}$ (central frequency for the DVB-T band).

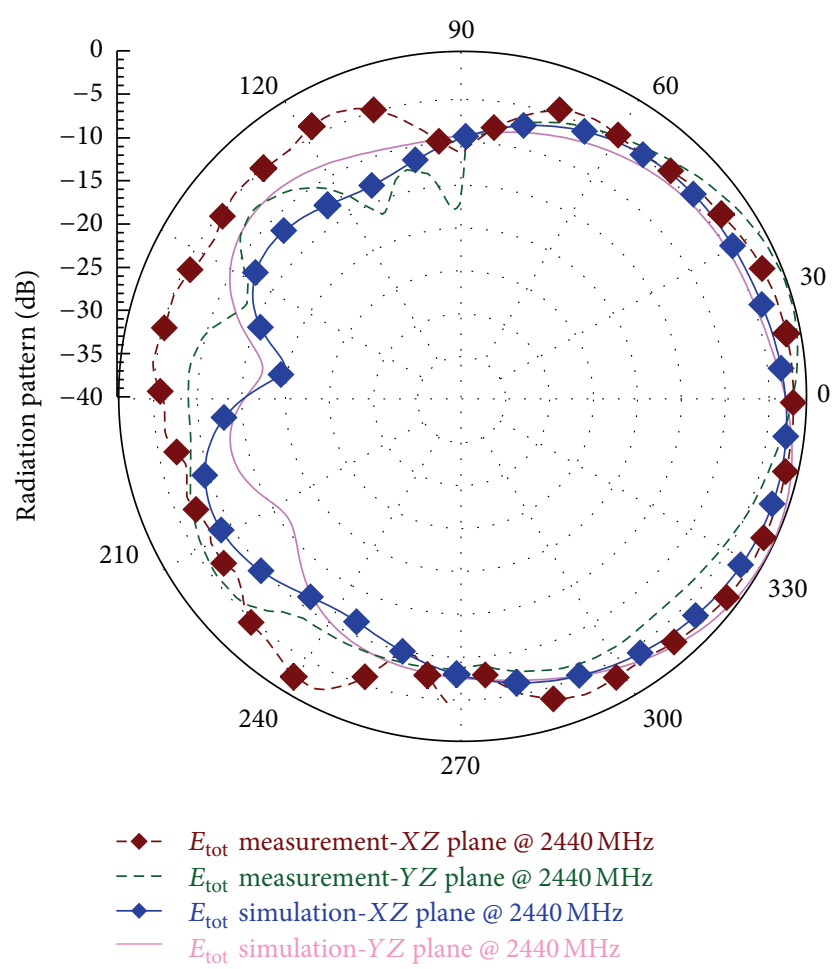

FIGURE 21: Simulated and measured radiation patterns (total E-field for the $X Z$ and $Y Z$ planes) for the proposed dual-band L-shape PIFA at $2440 \mathrm{MHz}$ (central frequency for the IEEE 802.11b,g band).
This confirms the robustness of the proposed L-shape PIFA design, which can be well optimized also when specific and demanding aesthetic/mechanical requirements must be met.

\section{References}

[1] DVB Project, http://www.dvb.org/.

[2] K. L. Wong, C. I. Lin, T. Y. Wu, and J. W. Lai, "A planar DTV receiving antenna for laptop applications," Microwave and Optical Technology Letters, vol. 42, no. 6, pp. 483-486, 2004.

[3] C. M. Su, L. C. Chou, C. I. Lin, and K. L. Wong, "Internal DTV receiving antenna for laptop application," Microwave and Optical Technology Letters, vol. 44, no. 1, pp. 4-6, 2005.

[4] Y. W. Chi and K. L. Wong, "Wideband printed dipole antenna for DTV signal reception," in Proceedings of IEEE Region 10 Conference (TENCON '07), pp. 1-4, November 2007.

[5] W. S. Chen, Y. T. Chen, H. T. Chen, and J. S. Kuo, "A wideband printed monopole antenna for wireless applications," in Proceedings of IEEE International Symposium on Antennas and Propagation and USNC/URSI National Radio Science Meeting (APSURSI '09), June 2009.

[6] C. Yang, J. Kim, H. Kim, J. Wee, B. Kim, and C. Jung, "Quadband antenna with high isolation MIMO and broadband SCS for broadcasting and telecommunication services," IEEE Antennas and Wireless Propagation Letters, vol. 9, pp. 584-587, 2010.

[7] C. Y. Huang, B. M. Jeng, and J. S. Kuo, "Grating monopole antenna for DVB-T applications," IEEE Transactions on Antennas and Propagation, vol. 56, no. 6, pp. 1775-1776, 2008.

[8] C. Y. Huang, B. M. Jeng, and C. F. Yang, "Wideband monopole antenna for DVB-T applications," Electronics Letters, vol. 44, no. 25, pp. 1448-1450, 2008.

[9] L. Low, J. Batchelor, R. Heaton, and N. Chen, "Dual patches microstrip fed antenna with wide bandwidth," in Proceedings of the Loughborough Antennas and Propagation Conference (LAPC '09), pp. 429-432, November 2009.

[10] M. Koubeissi, Mouhamadou, C. Decroze, D. Carsenat, and T. Monédière, "Triband compact antenna for multistandard terminals and user's hand effect," International Journal of Antennas and Propagation, vol. 2009, Article ID 491262, 7 pages, 2009.

[11] J. K. Wee, J. W. Park, I. S. Yeom, B. G. Kim, and C. W. Jung, "Compact DVB-H antenna with broad dual-band operation for PMP applications," IEEE Antennas and Wireless Propagation Letters, vol. 9, pp. 580-583, 2010.

[12] H. T. Chattha, Y. Huang, and Y. Lu, "PIFA bandwidth enhancement by changing the widths of feed and shorting plates," IEEE Antennas and Wireless Propagation Letters, vol. 8, pp. 637-640, 2009.

[13] C. See, H. Hraga, R. Abd-Alhameed, N. McEwan, J. Noras, and P. Excell, "A low-profile ultra-wideband modified planar invertedF antenna," IEEE Transactions on Antennas and Propagation, vol. 61, no. 1, pp. 100-108, 2012.

[14] C. Suárez-Fajardo, J. O. Gómez-Sará, and M. Ferrando-Bataller, "Broadband PIFA with capacitive feed," in Proceedings of IEEE International Symposium on Antennas and Propagation and USNC/URSI National Radio Science Meeting (APSURSI '09), pp. 1-4, June 2009.

[15] H. Chaobin and Z. Qi, "A compact wideband PIFA for dualband WLAN applications," in Proceedings of the International Conference on Microwave and Millimeter Wave Technology (ICMMT '12), vol. 4, pp. 1-4, May 2012. 
[16] C. H. See, R. A. Abd-Alhameed, D. Zhou, and P. S. Excell, "A planar inverted-f-l antenna (pifla) with a rectangular feeding plate for lower-band uwb applications," IEEE Antennas and Wireless Propagation Letters, vol. 9, pp. 149-151, 2010.

[17] P. Nepa, G. Manara, A. A. Serra, and G. Nenna, "Multiband PIFA for WLAN mobile terminals," IEEE Antennas and Wireless Propagation Letters, vol. 4, no. 1, pp. 349-350, 2005.

[18] R. Caso, A. D’Alessandro, A. A. Serra, P. Nepa, and G. Manara, "An integrated dual-band PIFA for DVB-T and WiMAX applications," IEEE Antenna and Wireless Propagation Letters, vol. 10, pp. 1027-1030, 2011.

[19] R. Caso, A. D’Alessandro, A. A. Serra, P. Nepa P, and G. Manara, "A compact dual-band PIFA for DVB-T and WLAN applications," IEEE Transaction on Antennas and Propagation, vol. 60, no. 4, pp. 2084-2087, 2012.

[20] R. Caso, A. D’Alessandro, A. A. Serra, P. Nepa, and G. Manara, "Dual-band integrated G-PIFA antenna for DVB-T and WLAN applications," in Proceedings of IEEE International Symposium on Antennas and Propagation, Spokane (AP-S '11), Washington, DC, USA, July 2011. 

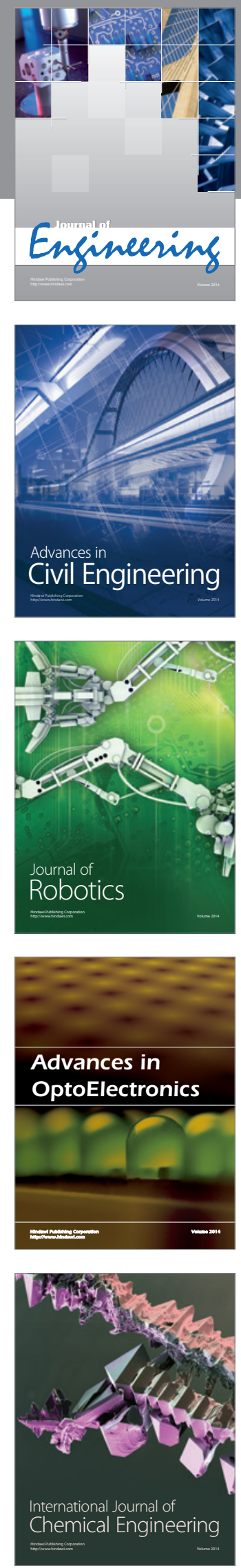

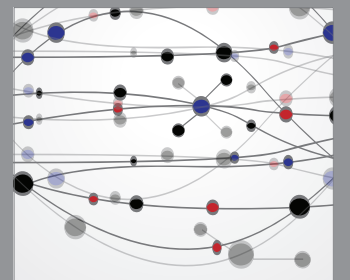

The Scientific World Journal
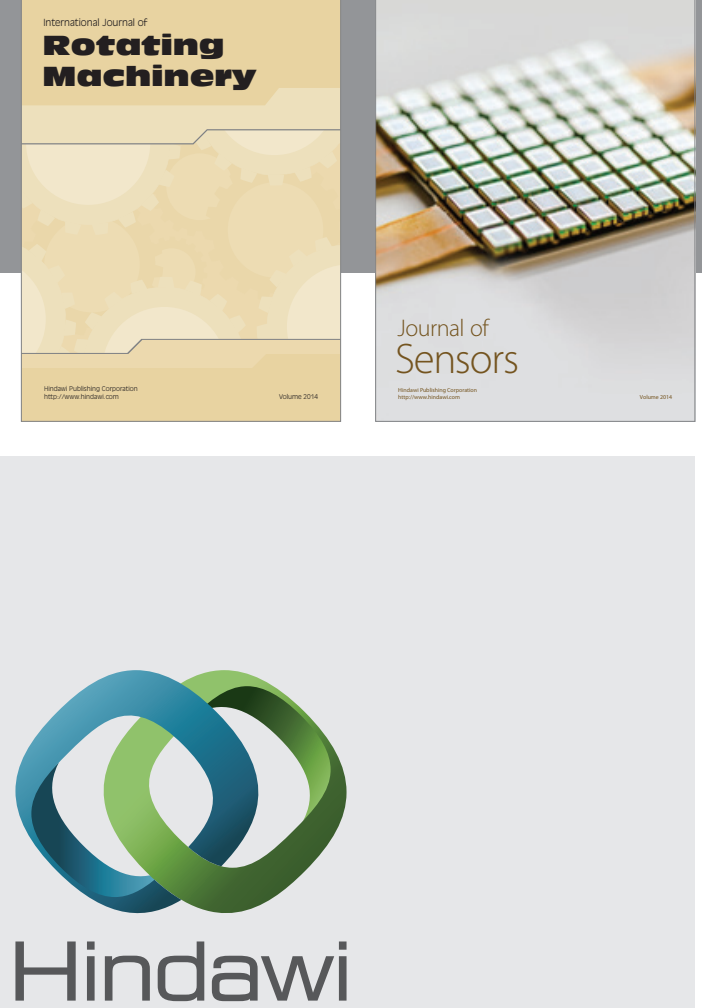

Submit your manuscripts at http://www.hindawi.com
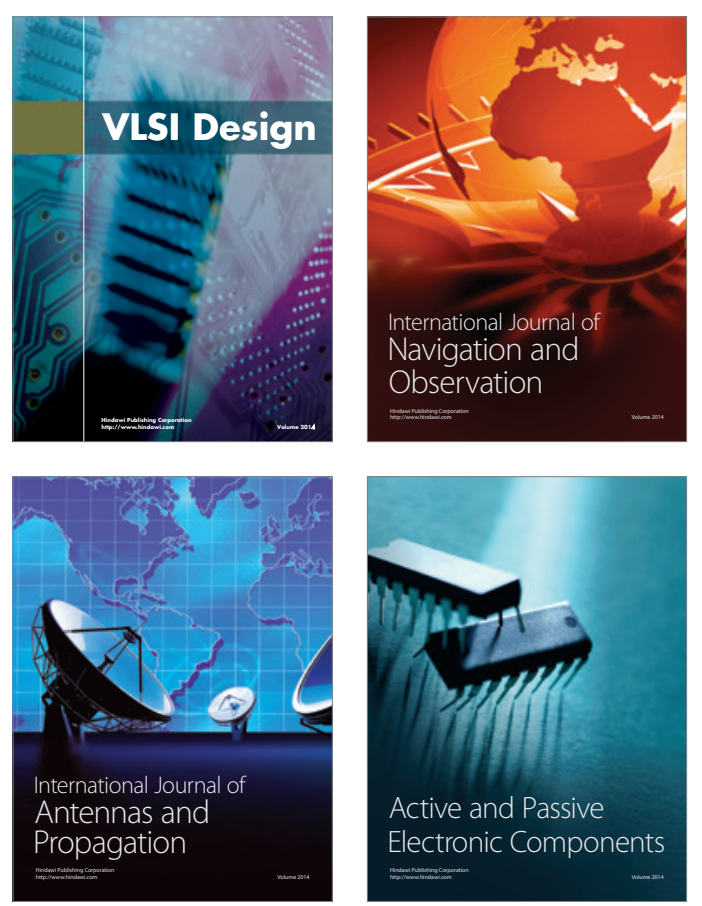
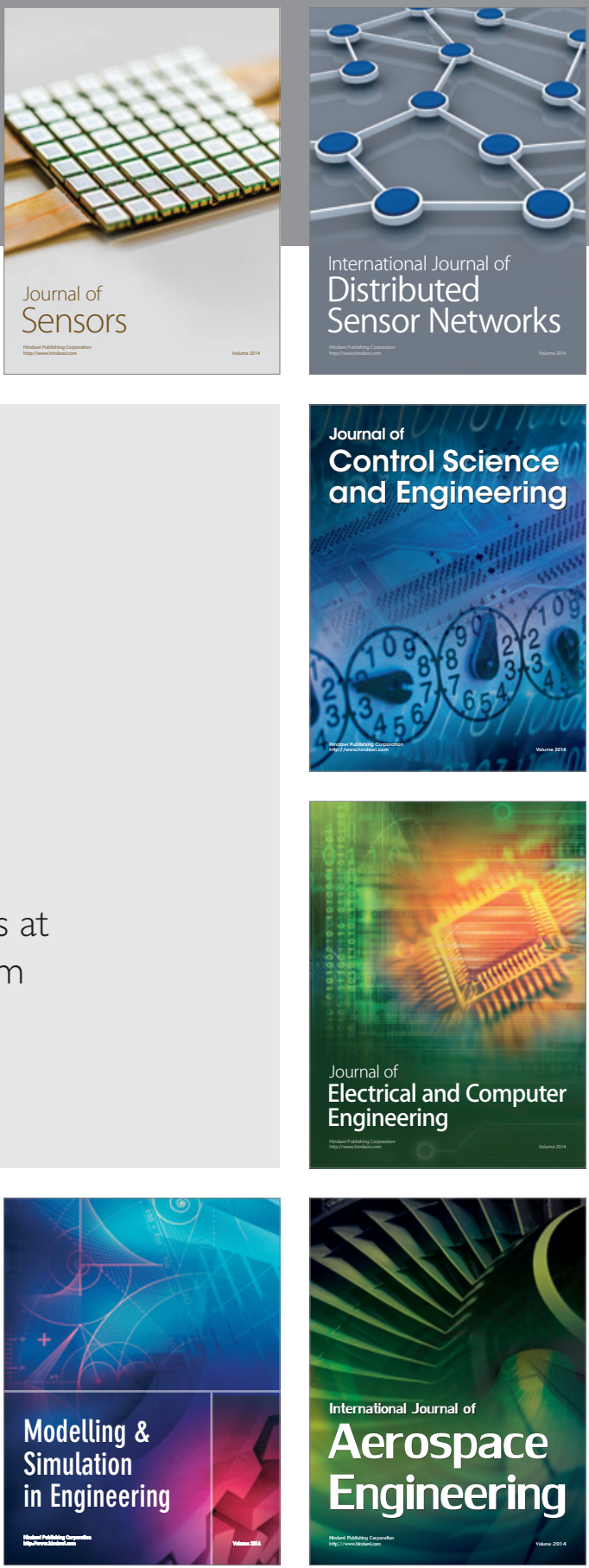

Journal of

Control Science

and Engineering
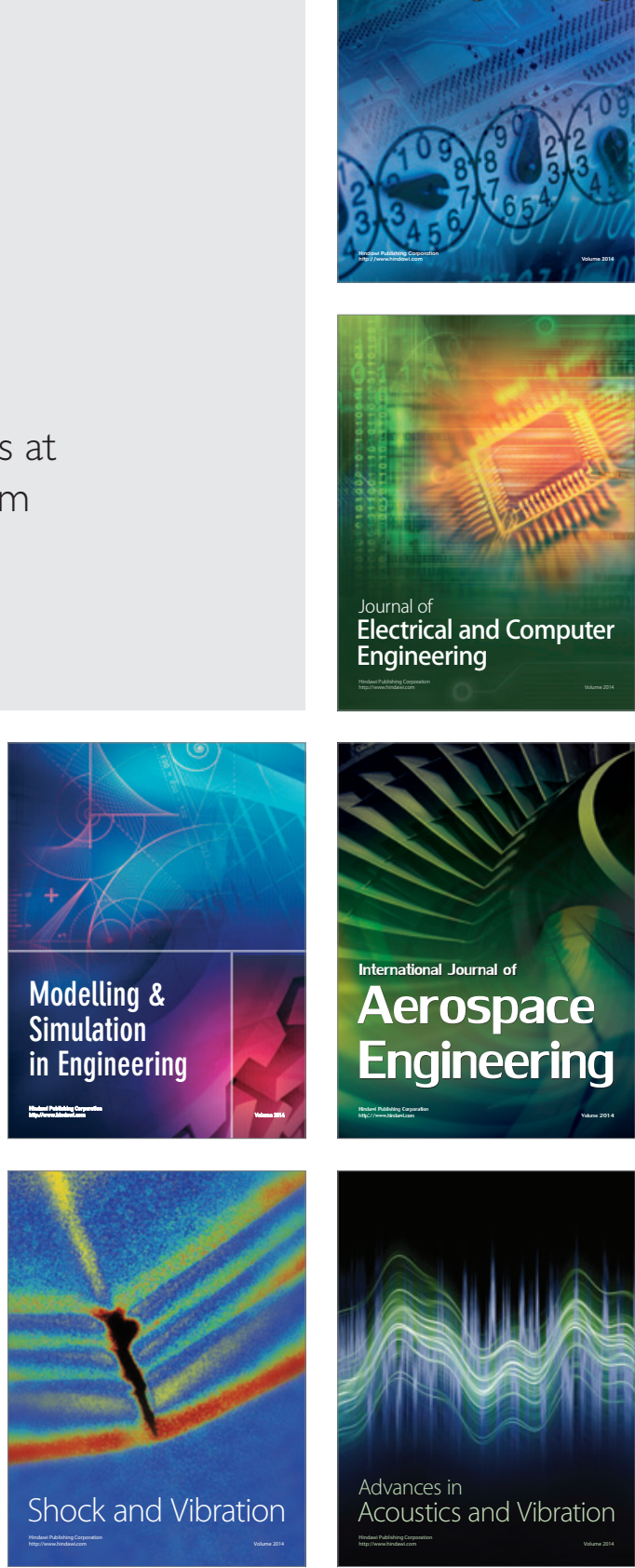